\title{
Sexual Fluidity and Attitudes towards Bisexuality
}

\author{
SERENA SBRANA \\ sbranaserena91@gmail.com
}

\author{
AdELIA DE MigueL \\ admiguel@ull.es
}

University of La Laguna

\begin{abstract}
The following research provides an instrument to assess sexual fluidity changes over time in attractions and sexual orientation identity, thus examining whether experiencing sexual fluidity is related to specific cognitions, attitudes and beliefs among sexually and non-sexually fluid individuals. Participants (435 Spanish young adult students, 310 females and 125 males) completed an online form assessing demographic data, sexual orientation, sexual fluidity, and attitudes towards male and female bisexuality. An empirical sexual fluidity factor has been isolated: women scored higher than men $(d=.68)$, and bisexual people higher than the homosexual $(d=1.74)$ and heterosexual $(d=1.40)$ groups. The study also highlights gender, sexual orientation and sexual fluidity differences in attitudes towards male and female bisexuality. Indeed, women consider male and female bisexuality more stable than men ( $d$ $=.29 \& d=.34$ ); sexually fluid people show higher positive attitudes towards male and female bisexuality ( $d$ ranged $.29-.51$ ) than the non-sexually fluid group; bisexual individuals scored higher in male and female bisexuality attitudes than heterosexual individuals. This study confirms previous research that showed that female individuals are more likely than male to have fluid sexuality. Attitudes about bisexuality are not a simple question: they are affected by gender, sexual orientation and sexual fluidity factors.
\end{abstract}

\section{Introduction}

The literature has underlined a series of controversial issues related to bisexuality, starting from its very understanding as a form of sexual orientation. Indeed, several studies show that bisexuality can be regarded as a stable and different sexual orientation from heterosexuality and homosexuality (Rieger, Chivers and Bailey, 2005; Chivers, Seto and Blanchard, 2007; Rieger and Savin-Williams, 2012). Research on sexual minority women (Diamond, 2008) has introduced the change of sexual orientation identity (sexual fluidity) in women as a capacity for situation-dependent flexibility in sexual responsiveness, allowing individuals to experience changes in same-sex or other-sex desire across both short-term and long-term periods. A growing body of research on sexual fluidity reveals that women are more sexually fluid than men (Kinnish, Strassberg and Turner, 2005; Diamond, 2008; Diamond, 2016). 
Sexual fluidity and bisexuality produce the same phenomenological result: sexual attractions for men and women. The difference between these constructs is the nature of the phenomenon. Sexual fluidity is a capacity for change in erotic responsiveness, dependent on the context and life events; in contrast, bisexuality is a stable sexual predisposition with regular experience of non-exclusive desires. Sexual fluidity represents a capacity to change in attraction, and it is context-dependent, and bisexuality could be a pattern of mixed attractions. The purposes of the present study are several: (a) to construct and validate a new quantitative measure of sexual fluidity; (b) to contribute to the literature on sexual fluidity and attitudes towards bisexuality; (c) to understand if the attitudes towards bisexuality can be related to a possible change in sexual orientation. The construct of sexual fluidity and the research on this topic will be first introduced and critically discussed in the ensuing sections. The following ones will then address attitudes to bisexuality and sexual fluidity and draw a possible connection between bisexuality and sexual fluidity.

\section{Sexual fluidity}

The Institute of Medicine (IOM, 2011) defines sexual orientation as a multi-dimensional construct composed of attractions, sexual behaviour and sexual orientation identity. Sexual fluidity has been defined as situationally dependent flexibility in sexual responsiveness that may manifest in changes in sexual orientation (Diamond, 2008), with sexual responsiveness further operationalised as attractions, desires and attitudes. The existence of sexual fluidity does not mean that everybody is bisexual or that bisexuality does not exist. Only few people have experienced this model of sexual orientation, just a small part of the people, but not all of them.

Several studies using cross-sectional and longitudinal designs have looked at the differences in sexual attractions over time and found that the prevalence of non-exclusive vs. exclusive same-sex attraction differs for men vs. women. Higher rates of non-exclusive attraction were detected among women than among men (Diamond, 2016).

If non-exclusive patterns of same-sex attractions are more common in women than in men, it is not clear why there is this gender difference. One of the reasons can be the fundamental sex difference that could make women more likely than men to experience bisexual arousal. The heightened sexual fluidity in women can be explained by the changes over time in changes in attractions (Kinnish, Strassberg and Turner, 2005) and by the difference in their levels of genital to sexual stimuli for 'non-preferred' gender than men who have higher levels of genitals for the 'preferred' gender stimuli (Chivers, Rieger, Latty and Bailey, 2004; Chivers and Bailey, 2005; Chivers, Seto and Blanchard, 2007; Bouchard, Timmers and Chivers, 2015). Both lesbian and heterosexual women show similar levels of genital arousal to 'preferred' and 'nonpreferred' sex stimuli. In contrast, men show higher levels to 'preferred' sex and less genital arousal to their 'non-preferred' sex. There are potential evolutionary reasons for this gender difference, but there is no common point of view (Baumeister, 2000; Chivers, Seto and Blanchard, 2007; Kuhle and Radke, 2013).

Additionally, the social and cultural factors can explain the gender difference in a nonexclusive attraction. Historically, male individuals were freer to expose their sexuality than female ones, whose sexuality has been subjected to far greater control (Baumeister and Twenge, 2002). Furthermore, the social and economic costs were so high to renounce 
traditional roles as wives and mothers that for women who adopted a same-sex behaviour, it was easier and safer to have same-sex contact in heterosexual behaviour. At the same time, the data show how the increase of social acceptance of same-sex sexuality can influence sexual attraction and behaviour expressions (Twenge, Sherman and Wells, 2015, 2016).

Sexual fluidity includes a change in every sexual orientation direction. The data of previous research evidence sexual fluidity among heterosexually-identified and other-gender attracted individuals (Dickson et al., 2003, 2013; Ott et al., 2011; Mock and Eibach, 2012; Savin-Williams et al., 2012; Katz-Wise, 2014). Sexual fluidity is not limited to sexual minorities but can be a process for individuals who first define themselves as heterosexual but then indicate some evidence of same-gender sexual orientation.

In the literature, there are studies based on qualitative analysis (Baumeister 2000; Diamond, 2003) or big scale American national research (Chandra et al., 2011; Wells, McGee and Beautrais, 2011; Dahlhamer et al., 2014, 2015; Gorman et al., 2015), but there is not any empirical support for the sexual fluidity dimension.

\section{Attitudes towards bisexuality}

A large body of investigations has proven the existence of negative attitudes and prejudices towards bisexual individuals (Israel and Mohr, 2004), specifically towards bisexual men (Eliason, 2001; Herek, 2002; Yost and Thomas, 2012). Bennet (1992) coined the term 'biphobia' to describe a set of prejudiced attitudes about bisexual sexual orientation individuals. Biphobia is not the fear of individuals with bisexual orientation, as the word suggests, but the presence of sexual prejudices and negative attitudes towards bisexual people. For this reason, 'binegativity' is the best term to describe this form of denigration. The beliefs that bisexual people (more specifically, bisexual male individuals) are confused about their sexual identity, that they are in reality gay or lesbian, immature, emotionally incomplete, sexually promiscuous, unable to be monogamous or more likely to contract HIV/AIDS, are included in the binegativity concept (Sumpter, 1991; Farajaje'-Jones, 1995; Ochs, 1996; Rust, 2002; Yost and Thomas, 2012). Binegativity is expressed in the same way by heterosexual and homosexual individuals (Weiss, 2004; Zinovy and Lobel, 2014).

The cognitions related to bisexuality can be an essential step toward understanding why some individuals experience sexual fluidity while others do not. Mohr and Rochlen (1999) investigated attitudes towards bisexuality in their study for the first time. Two forms of scales (i.e., Attitudes Regarding Bisexuality Scale [ARBS]) were created to assess attitudes about female (Attitudes Regarding Bisexuality Scale-Female [ARBS-F]) and male (Attitudes Regarding Bisexuality Scale-Male version [ARBS-M]) bisexuality. The most important factors were related to viewing bisexuality as a tolerable, moral sexual orientation (Tolerance) and a legitimate, stable sexual orientation (Stability). However, no current studies are investigating how sexual fluidity can influence the acceptance or refusal of male and female bisexuality.

\section{The present study}

The first objective of this research is to provide an instrument to assess the construct of sexual fluidity. For this purpose, the Sexual Fluidity Scale (SFS) was then created, which comprises 
17 items. More specifically, in order to assess behaviour, desire and attitudes towards sexual fluidity, items 1-7 and 13-17 were created using Diamond's (2003) theorisation. On the other hand, items 8-12, which just refer to attitudes towards sexual fluidity, were developed on the basis of the Sexual Fluidity Beliefs Scale (SFBS; see Kats-Wise and Hyde, 2015). All of the items were rated on a 5 -point rating scale $(1=$ strongly disagree to $5=$ strongly agree), a higher score indicating a more positive attitude towards sexual fluidity (see Table 4.1):

\begin{tabular}{|c|c|c|c|c|c|}
\hline & & $M$ & $S D$ & $F$ & $h^{2}$ \\
\hline \multicolumn{6}{|c|}{ Behaviour } \\
\hline 1. & $\begin{array}{l}\text { Creo que en un contexto desprovisto de presión social, } \\
\text { yo podría tener una relación sexual con una persona del } \\
\text { género que normalmente no prefiero. }\end{array}$ & 2.43 & 2.45 & .64 & .41 \\
\hline
\end{tabular}

I believe that, in a comfortable context without social pressure, I could have a sexual relationship with a person whose gender is not the one I usually prefer.
2. Creo que mi orientación sexual podría cambiar en función de la situación en la que estuviera.

$\begin{array}{llll}2.32 & 1.37 & .69 & .47\end{array}$

I believe that my sexual orientation could vary depending on the situation I find myself in.

$\begin{array}{llllll}\text { 3. Me gustaría tener una relación sexual con una persona } & 2.43 & 1.43 & .77 & .60 \\ \text { que no fuera de mi género preferido. }\end{array}$

I would like to have a sexual relationship with a person whose gender is not my preferred gender.

$\begin{array}{llllll}\text { 4. Creo que la conducta sexual en sí misma no es el } & 3.27 & 1.32 & .50 & .25 \\ \text { resultado de la orientación sexual. }\end{array}$

I believe that my sexual behaviour is not the result of sexual orientation.

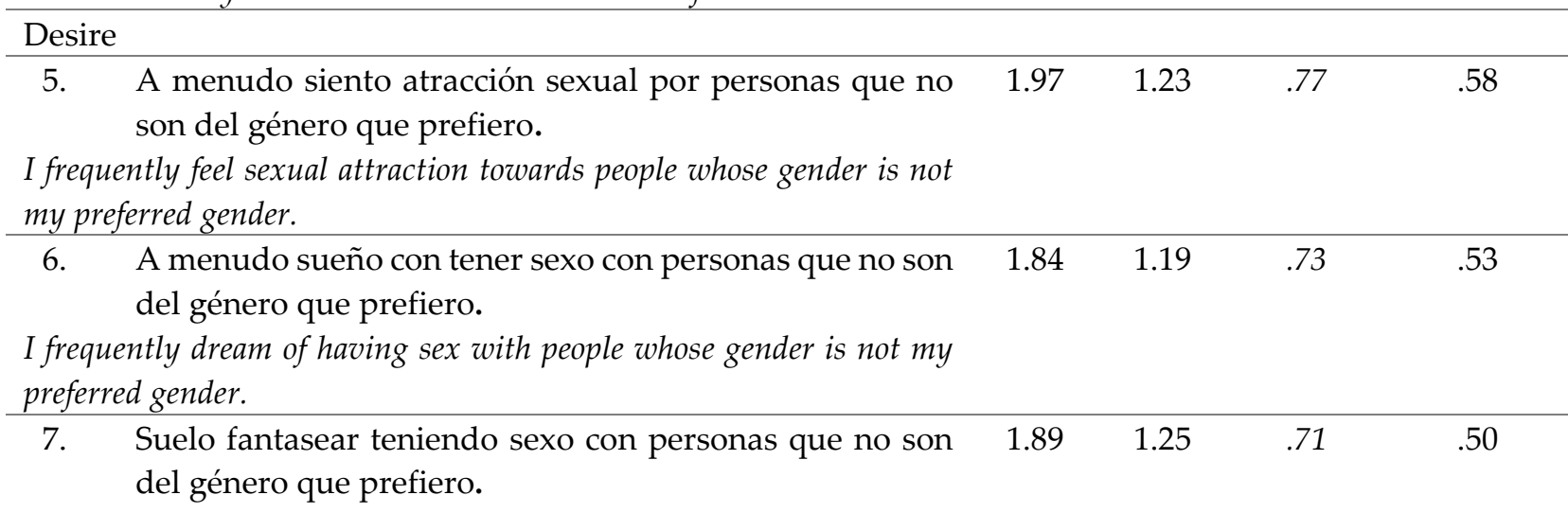

I tend to fantasise about having sex with people whose gender is not my

preferred gender.

Attitudes

8. Siento que mi orientación sexual es algo que yo elegí. $\quad \begin{array}{lllllll}3.05 & 1.64 & -.03 & .01\end{array}$

I feel that my sexual orientation is something I have chosen.

9. Creo que el amor romántico depende de la persona y no
del género que tenga.

I believe romantic love depends on the person, not the gender.

\begin{tabular}{|c|c|c|c|c|}
\hline $\begin{array}{l}\text { 10. No se el género de la persona por quien me sentiré } \\
\text { atraído/a en el futuro. }\end{array}$ & 3.11 & 1.60 & .81 & .65 \\
\hline 11. No sé cómo definiré mi orientación sexual en el futuro. & 2.70 & 1.50 & .69 & .47 \\
\hline
\end{tabular}


I don't know how I will label my sexual orientation in the future.

12. Siento que mi orientación sexual es fluida (que puede pasar de homosexual a heterosexual y viceversa, sin problema).

I feel my sexuality is fluid (it could change from homosexuality to heterosexuality, and vice versa, without problems).

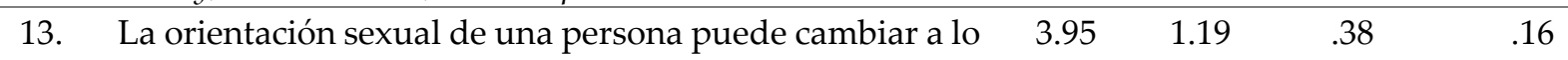
largo de su vida.

$\begin{array}{llll}M & S D & F & h^{2}\end{array}$

$\begin{array}{llll}2.16 & 1.41 & .76 & .58\end{array}$

The sexual orientation of a person may vary throughout their life.

$\begin{array}{llllll}\text { 14. Una persona puede decidir su propia orientación sexual. } & 3.23 & 1,59 & -.01 & .01\end{array}$ A person can decide their sexual orientation.

$\begin{array}{llllll}\text { 15. Una persona puede decidir si trasformar su deseo sexual } & 3.97 & 1.09 & .17 & \end{array}$ en una conducta sexual.

A person can decide if they want to change their sexual desire into sexual behaviour.

16. Una persona puede definirse como homosexual y tener una conducta sexual con una persona del género opuesto.

A person can define themselves as homosexual and display sexual behaviours with an opposite-gender person.

17. En una relación romántica no es importante el género de $\quad \begin{array}{lllll}4.28 & 1.12 & .33 & .11\end{array}$
la otra persona.

In a romantic relationship, the gender of the other person is not important.

Eigenvalue

Total variance explained

Table 4.1. Descriptive categories and factor structure in the sexual fluidity scale.

The second goal of this study is to analyse if the attitudes towards female and male bisexuality depend on gender, sexual fluidity and sexual orientation.

\section{Method}

\subsection{Participants}

The participants were 435 university students (310 females, 125 males), ages ranging 18-38 $(M=21.17, S D=4.37)$ from the University of [anonymised], Spain. The majority of individuals were attending Health Science courses (46.7\%), while the rest of the participants were studying Arts and Humanities (29.9\%), Science (29.9) and Law and Communication (2.6\%) courses. Distribution regarding self-named sexual orientation was: $54 \%$ heterosexual women, $22.1 \%$ heterosexual men, $2.9 \%$ lesbian women, $3.6 \%$ gay men, $14.5 \%$ bisexual women, and $2.9 \%$ bisexual men.

\subsection{Instruments}


In the following paragraphs, the tools adopted for the present investigation are briefly described, starting with the Sexual Fluidity Scale (SFS), which is comprised of 17 items rated on a 5 -point rating scale $(1=$ strongly disagree to $5=$ strongly agree), a higher score indicating more positive attitude towards sexual fluidity (see above). The Attitudes Regarding Bisexuality Scale-Female (ARBS-F) and Scale-Male (ARBS-M) (Mohr and Rochlen, 1999) are, on the other hand, both scales consisting of 12 items: 6 items for the Stability subscales and 6 items for the Tolerance subscale. The items are rated on a 5 -point rating scale $(1=$ strongly disagree to $5=$ strongly agree), a higher score indicating a more positive attitude towards bisexuality. In this study, reliability for all items was $\alpha=.72$ for the female version and $\alpha=.74$ for the male version. Reliability for Tolerance scales were $\alpha=.70$ for the female version and $\alpha=.83$ for the male version. Reliability for Stability scales were $\alpha=.80$ and $\alpha=.81$, respectively.

\subsection{Procedure}

The online recruitment started in September and finished in December 2017. The project was presented in every Department at the University of [anonymised] to the students who could access the URL link by the virtual area of the University (by Department coordinators or student associations). Duration of the survey completion ranged between 20 to 40 minutes. On the first page, there was the description of the study and the informed consent to participate in the investigation. Any data about personal identification were recorded or asked. The statistical analyses were made with IBM SPSS 22.

\section{Results}

\subsection{Factor Analysis and internal reliability for FSF}

A principal component factor analysis was performed with $\mathrm{n}$-factor $=1$ for all item scores. Using the loading scores more than or equal to .40, the non-rotated factor extracted explained $32.5 \%$ of the variance (Table 4.1 ) and consisted of 10 of 17 items. The first four items were on behaviour (items 1, 2,3,4), the following three on desire (item 5, 6, 7) and the last three on attitudes (items 10,11,12). All loading scores were positive, assessing behaviour, desire and attitude as positive with reference to fluid sexuality. The items $8,9,13,14,15,16$ and 17 showed a loading under 0.40 , and they were removed for future analyses.

The reliability analysis was performed on the item scores loaded more than .40. Cronbach's alpha was .89. This value indicated a good level of internal consistency among 10 items. The alpha value did not increase after deleting any one of the items.

There were gender differences (women: $M=26.0, S D=9.46$; men: $M=19.53, S D=9.36 ; t=$ $6.48 ; p<.001 ; d=.68$ ) and sexual orientation differences between the bisexual group and the other two groups (homosexual: $M=19.39, S D=9.13$; heterosexual: $M=22.12, S D=9.07$; bisexual: $\left.M=33.61, S D=7.14 ; F_{1,43}=60.25, p<.001, \eta^{2}=.01\right)$. Cohen's $d$ was 1.74 for bisexual vs. homosexual individuals, and 1.40 for bisexual vs. heterosexual individuals.

\subsection{Attitudes towards bisexuality}


The sample was divided by gender (i.e., male and female), self-named sexual orientation (i.e., homosexual, bisexual, and heterosexual) and by sexual fluidity using the median score on the SFS. The individuals who got scores higher than median score $=23$ on the SFS were defined as 'sexually fluid', and those who got scores lower than such a median score were defined as 'non-sexually fluid'. 219 participants (i.e., 7 lesbian women, 4 gay men, 62 bisexual women, 10 bisexual men, 116 heterosexual women and 20 heterosexual men) were classified as sexually fluid, while 216 participants (i.e., 6 lesbian women, 12 gay men, 1 bisexual woman, 3 bisexual men, 118 heterosexual women and 76 heterosexual men) as non-sexually fluid. Table 6.2.1 shows this distribution, underlining that there are more sexually fluid women than sexually fluid men $\left(\chi^{2}{ }_{1}=33.25, p<.001\right)$.

Scores and reliability statistics for each scale and subscale of ARBS were also computed. Using $t$-tests, chi-square tests, and univariate tests (ANOVA), the differences between sexual fluidity groups (fluidity vs. non-fluidity), between gender groups (male vs. female) and among sexual orientation groups (homosexual, bisexual and heterosexual) were analysed. The effect size was calculated by Cohen's $d$ to determine the magnitude of sexual fluidity, gender and sexual orientation differences. The descriptive statistics and comparisons by gender, sexual fluidity and sexual orientation for the ARBS male and female versions are shown in Table 6.4.1, Table 6.4.2, and Table 6.4.3, respectively.

\begin{tabular}{llllll}
\hline & Women & \multicolumn{5}{c}{ Men } \\
\cline { 2 - 6 } & $\begin{array}{l}\text { Non-sexually } \\
\text { fluid }\end{array}$ & Sexually fluid & $\begin{array}{l}\text { Non-sexually } \\
\text { fluid }\end{array}$ & Sexually fluid & total \\
\hline Homosexual & 6 & 7 & 12 & 4 & $6.7 \%$ \\
Bisexual & 1 & 62 & 3 & 10 & $17.4 \%$ \\
Heterosexual & 118 & 116 & 76 & 20 & $75.9 \%$ \\
Total & $28.7 \%$ & $42.6 \%$ & $20.9 \%$ & $7.8 \%$ & $100 \%$ \\
\hline
\end{tabular}

Table 6.2.1. Distribution of participants by gender, sexual fluidity and sexual orientation.

\subsection{Attitudes towards female bisexuality}

Both men and women indicated similar positive attitudes towards female bisexuality $(t=2.74$, $p<.01)$ and, more specifically, regarding tolerance towards female bisexuality $(t=1.49$; see Table 6.4.1). However, the women group considered female bisexuality a more stable identity than the men group $(t=2.72, p<.01)$. As for sexual fluidity, sexually fluid individuals reported more positive attitudes towards female bisexuality if compared to non-sexually fluid individuals $(t=5.40, p<.001)$, in both the tolerance $(t=5.30, p<.001)$ and stability $(t=2.99, p<.001)$ subscales (Table 6.4.2). Finally, an ANOVA was conducted with sexual orientation as an independent variable and ARBS female version measures as dependent variables. In Table 6.4.3, results indicate significant sexual-orientation differences for ARBS-F total score $\left(F_{1,434}=\right.$ $\left.15.42, p<.001, \eta^{2}=.07\right)$, stability $\left(F_{1,434}=14.91, p<.001, \eta^{2}=.06\right)$ and tolerance $\left(F_{1,434}=15.84, p<.01\right.$, $\left.\eta^{2}=.02\right)$ subscales. Tukey's post-hoc analyses revealed that bisexual individuals scored higher on purpose in ARBS-F than homosexual individuals. This difference appeared for both 
subscales; in particular, there was a more statistically significant difference for the stability subscale.

\subsection{Attitudes towards male bisexuality}

Like in attitudes towards female bisexuality, women and men indicated similar positive attitudes towards male bisexuality $(t=3.08, p<.01)$ and stability subscale $(t=3.04, p<.01)$, but there was no significant difference in tolerance subscale (see Table 6.4.1). Sexually fluid individual scores indicate more positive attitudes towards the total score of female bisexuality $(t=4.42$, $p<.01)$ and subscale of tolerance $(t=3.40, p<.001)$ than non-sexually fluid individuals scores, but there is no difference for stability subscale (see Table 6.4.2). About sexual orientation, which was considered as an independent variable, the ANOVA showed significant differences for ARBS-M ( $\left.F_{1,434}=13.75, p<.001, \eta^{2}=.06\right)$, and stability $\left(F_{1,434}=13.67, p<.0, \eta^{2}=.06\right)$ and tolerance $\left(F_{1,434}=4.92, \quad p<.05, \eta^{2}=.02\right)$ subscales. Tukey's post-hoc analyses showed that bisexual individuals scored higher in ARBS-M (total score and both subscales) than homosexual individuals; in particular, there was a more statistically significant difference for stability subscale (see Table 6.4.3).

\begin{tabular}{|c|c|c|c|c|c|c|}
\hline & \multicolumn{2}{|c|}{ Women } & \multicolumn{2}{|c|}{ Men } & \multirow[b]{2}{*}{$t$} & \multirow[b]{2}{*}{$d$} \\
\hline & Mean & SD & Mean & SD & & \\
\hline Attitudes towards female bisexuality & 4.47 & .50 & 4.33 & .52 & $2.74^{* *}$ & .30 \\
\hline Stability & 4.15 & .77 & 3.93 & .76 & $2.72^{* *}$ & .29 \\
\hline Tolerance & 4.80 & .44 & 4.72 & .54 & 1.49 & .16 \\
\hline Attitudes towards male bisexuality & 4.40 & .54 & 4.22 & .57 & $3.08^{* *}$ & .32 \\
\hline Stability & 3.98 & .81 & 3.71 & .78 & $3.04^{* *}$ & .34 \\
\hline Tolerance & 4.82 & .46 & 4.72 & .56 & 1.72 & .20 \\
\hline
\end{tabular}

${ }^{*} p<.05 ;{ }^{* *} p<.01 ; * * * p<.001$

Table 6.4.1. Gender differences in ARBS male and female versions.

\begin{tabular}{|c|c|c|c|c|c|c|}
\hline & \multicolumn{2}{|c|}{ Non-sexually fluid } & \multicolumn{2}{|c|}{ Sexually fluid } & \multirow[b]{2}{*}{$t$} & \multirow[b]{2}{*}{$d$} \\
\hline & Mean & SD & Mean & $\mathrm{SD}$ & & \\
\hline Attitudes towards female bisexuality & 4.31 & .57 & 4.56 & .40 & $5.40^{* * *}$ & .50 \\
\hline Stability & 3.90 & .81 & 4.28 & .66 & $5.30^{* * *}$ & .51 \\
\hline Tolerance & 4.71 & .56 & 4.84 & .32 & $2.99^{* * *}$ & .29 \\
\hline Attitudes towards male bisexuality & 4.22 & .60 & 4.47 & .46 & $4.42^{* *}$ & .47 \\
\hline
\end{tabular}




\begin{tabular}{|c|c|c|c|c|c|c|}
\hline & \multicolumn{2}{|c|}{ Non-sexually fluid } & \multicolumn{2}{|c|}{ Sexually fluid } & \multirow[b]{2}{*}{$t$} & \multirow[b]{2}{*}{$d$} \\
\hline & Mean & SD & Mean & SD & & \\
\hline Stability & 3.73 & .82 & 4.07 & .75 & 4.42 & .43 \\
\hline Tolerance & 4.71 & .59 & 4.87 & .35 & $3.40^{* * *}$ & .33 \\
\hline
\end{tabular}

${ }^{*} p<.05 ;{ }^{* *} p<.01 ; * * * 0.001$

Table 6.4.2. Sexual fluidity differences in ARBS male and female versions.

\begin{tabular}{lccccccccc}
\hline & $\begin{array}{c}\text { Homosexual } \\
(1)\end{array}$ & \multicolumn{2}{c}{$\begin{array}{c}\text { Bisexual } \\
(2)\end{array}$} & \multicolumn{2}{c}{$\begin{array}{c}\text { Heterosexual } \\
(3)\end{array}$} \\
\cline { 2 - 9 } & Mean & SD & Mean & SD & Mean & SD & $F$ & Scheffe \\
\hline $\begin{array}{l}\text { Attitudes towards female } \\
\text { bisexuality }\end{array}$ & 4.60 & .38 & 4.69 & .32 & 4.36 & .54 & $15.42^{* * *}$ & $2>3^{* * *}$ \\
$\begin{array}{l}\text { Stability } \\
\text { Tolerance }\end{array}$ & 4.28 & .67 & 4.47 & .59 & 3.98 & .78 & $14.91^{* * *}$ & $2>3^{* * *}$ \\
$\begin{array}{l}\text { Attitudes towards male } \\
\text { bisexuality }\end{array}$ & 4.91 & .21 & 4.90 & .21 & 4.74 & .52 & $4.84^{* *}$ & $2>3^{*}$ \\
$\begin{array}{l}\text { Stability } \\
\text { Tolerance }\end{array}$ & 4.04 & .54 & 4.61 & .34 & 4.27 & .57 & $13.75^{* * *}$ & $2>3^{* * *}$ \\
& 4.90 & .27 & 4.93 & .18 & 4.75 & .55 & $4.92^{* *}$ & $2>3^{*}$ \\
\hline
\end{tabular}

${ }^{*} p<.05 ;{ }^{* *} p<.01 ; * * * 0.001$

Table 6.4.3. Sexual orientation differences in ARBS male and female versions.

\section{Discussion}

In the first part of the present study, using Diamond's qualitative interviews and Kate-Wise and Hyde's Sexual Fluidity Beliefs Scale, the empirical operationalisation of sexual fluidity was initially composed of 17 items. The final factor structure consisted of 10 items loading more .40 in a single factor: four behaviour items (i.e., I would like to have a sexual relationship with a person whose gender is not from my preferred gender), and three desire items (i.e., Frequently I feel sexual attraction towards people whose gender is not from my preferred gender), based on Diamond's approach and three attitude items taken from Kate-Wise and Hyde's (i.e., I don't know the gender of the person to whom I will be attracted to in the future). The new Sexual Fluidity Scale (SFS) instrument was then developed to assess beliefs on sexual fluidity and the possibility to identify sexually and non-sexually fluid people. In this preliminary study, the features of the Sexual Fluidity Scale were appropriate to describe the construction of sexual fluidity. The good level of internal consistency ensures a robust factor to assess fluid sexuality. The sample was heterogeneous, and additionally, the three more common sexual orientations were considered 
in the study (heterosexual, bisexual and homosexual), thus not only focusing our attention on sexual minorities. The results indicated differences between men and women in sexual fluidity: there are more sexually fluid women than sexually fluid men, thus confirming women's greater predisposition towards sexual fluidity (Kinnish, Strassberg and Turner, 2005; Diamond, 2008; Diamond, 2016).

The second goal of this study was to analyse possible differences in attitudes towards male and female bisexuality by gender, sexual fluidity and sexual orientation. As for gender, women showed more positive attitudes in ARBS (for male and female versions) than men, in accordance with previous research (Yost and Thomas, 2012; Katz-Wise and Hyde, 2015). There was no difference in tolerance. Women reported positive scores for items that consider bisexuality a stable orientation in life. In general, both men and women showed positive attitudes towards bisexuality in contrast with Mulick and Wright (2002), who found that male individuals showed negative attitudes towards bisexuality. Previous studies suggested that cognitions of bisexual male individuals by male individuals were related to fears of homosexuality and femininity, demonstrating that conforming to masculine norms is disdained by homosexual individuals (Mahalik et al., 2003). This new situation could reflect changes in societal and cultural views towards bisexuality, even if men have more difficulty defining themselves as bisexual than women. Furthermore, positive attitudes towards male bisexuality would not reflect the social prejudices towards male bisexuality (Zinovy and Lobel, 2014). As for sexual fluidity, sexually fluid individuals reported more positive attitudes in ARBS than non-sexually fluid. The student's test method to different variance has been used because the sexually fluid group was more heterogeneous in their responses (i.e., low standard deviation) than the non-sexually fluid group (i.e., high standard deviation). There were no significant differences between the groups on male bisexuality as a stable identity. Probably, this can reflect cultural stereotypes about male bisexuality as a transitional condition before a future stable homosexual or heterosexual orientation identity is adopted. Female bisexuality was considered more positively than male bisexuality. This can be interpreted as greater freedom to express their own sexual identity and behaviour that women benefit from the cultural ideas in society. Male bisexuality was valued as a stable orientation, and it was tolerated, compared to previous studies (Eliason, 2001; Yost and Thomas, 2012; Pirlott and Neuberg, 2014). Additionally, responses may also reflect social desirability bias or lack of knowledge, not being sure, or the participants not caring. As for sexual orientation, there is a significant difference in attitudes towards bisexuality between the bisexual group and the heterosexual group. Bisexual individuals report higher scores than heterosexual ones: being bisexual is connected with a positive view towards bisexuality.

Defining oneself as sexually fluid can determine a good feeling for people belonging to a minority category. People may view male sexuality in more binary terms than female sexuality due to simplified lay interpretations of sexual plasticity/fluidity in women (Diamond, 2008). This sees bisexual women as more prototypical of bisexual people.

In this study, a number of limitations should be mentioned. First, concerning the sample, university young students were recruited. Future research should include mature adults $(+30$ years old) with different features. Additionally, the new instrument created to assess sexual fluidity and used in this research could be compared with a real change of sexual attraction, desire and behaviour in the participant's life. Finally, the cross-sectional study design cannot determine the direction of the relationship attitudes towards bisexuality with the real change 
related to sexual fluidity. Therefore, a longitudinal study could be performed to investigate the actual qualitative direction of sexual fluidity.

\section{Conclusion}

In this study, a new scale to measure sexual fluidity was created based on Diamond's (2003, 2005) work. There are more sexually fluid women than sexually fluid men, supporting previous research underlining women's greater predisposition to sexual fluidity (Kinnish, Strassberg, and Turner, 2005; Diamond, 2008, 2016). Women reported more positive attitudes towards male and female bisexuality than men. Sexually fluid individuals reported more positive scores in male and female ARBS versions. One of the reasons that can explain this more positive point of view can be the introduction of education programs in the Spanish scholarship model (BOE, 2014). In those programs, education towards various sexual orientations is imparted with different teaching methods. There is also greater visibility of sexual orientation variance in daily Spanish TV shows. Students, who will become future adults, have the possibility to reflect on the topic of sexual orientation and free expression of themselves (Gobierno de Canarias, 2017).

\section{Keywords}

sexual fluidity; sexual orientation; assessment; bisexuality; gender

\section{References}

Baumeister, R.F. (2000), "Gender Differences in Erotic Plasticity: The Female Sex Drive Associally Flexible and Responsive", Psychological Bulletin, 126: 347-374. DOI: 10.1037/0033-2909.126.3.347.

Baumeister, R.F., and Twenge, J.M. (2002), "Cultural Suppression of Female Sexuality", Review of General Psychology, 6: 166-203. DOI: 10.1037/1089-2680.6.2.166.

Bennett, K. (1992), "Feminist Bisexuality: A both/and Option for an either/or World", in E.R. Weise (ed.), Close to Home: Bisexuality and Feminism, pp. 205-231, Seattle, WA: Seal Press.

Bouchard, K.N., Timmers, A.D., and Chivers, M.L. (2015), “Gender-Specificity of Genital Response and Self-Reported Sexual Arousal in Women Endorsing Facets of Bisexuality", Journal of Bisexuality, 15: 180-203. DOI: 10.1080/15299716.2015.1022924.

Chandra, A., Mosher, W.D., Copen, C., and Sionean, C. (2011), Sexual Behavior, Sexual Attraction, and Sexual Identity in the United States: Data from the 2006-2008 National Survey of Family Growth. National Health Statistics Reports, 36, Hyattsville, MD: National Center for Health Statistics.

Chivers, M.L., and Bailey, J.M. (2005), "A Sex Difference in Features That Elicit Genital Response”, Biological Psychology, 70: 61-79. DOI: 10.1016/j.biopsycho.2004.12.002.

Chivers, M.L., Riger, G., Latty, E., and Bailey, J.M. (2004), “A Sex Difference in the Specificity of Sexual Arousal", Psychological Science, 15: 736-744. DOI: 10.1111/j.09567976.2004.00750.x. 
Chivers, M.L., Seto, M.C., and Blanchard, R. (2007), "Gender and Sexual Orientation Differences in Sexual Response to Sexual Activities versus Gender of Actor in Sexual Film", Journal of Personality and Social Psychology, 93: 1108-1121. DOI: 10.1037/00223514.93.6.1108.

Dahlhamer, J.M., Galinsky, A.M, Joestl, S.S., and Ward, B.W. (2014), "Sexual Orientation in the 2013 National Health Interview Survey: A Quality Assessment", Vital Health Statistics, 2 (169): 1-24.

Diamond, L.M. (2008), Sexual Fluidity: Understanding Women's Love and Desire, London: Harvard University Press.

Diamond, L.M. (2016), "Sexual Fluidity in Male and Female". Current Sexual Health Reports, 8 (4): 249-256. DOI: 10.1007/s11930-016-0092-z.

Diamond, L.M., and Savin-Williams, R.C. (2003), "Explaining Diversity in the Development of Same-Sex Sexuality among Young Women", in L.D. Garnets and D.C. Kimmel (eds), Psychological Perspectives on Lesbian, Gay, and Bisexual Experiences ( ${ }^{\text {nd }}$ edn.), pp. 130-148, New York, NY: Columbia University Press.

Dickson, N., Roode, N., and Cameron, C. (2013), "Stability and Change in Same-Sex Attraction, Experiences, and Identity by Sex and Age in a New Zealand Birth Cohort", Archive of Sex Behavior, 42: 753-763. DOI: 10.1007/s10508-012-0063-z.

Eliason, M. (2001), “Bi-Negativity: The Stigma Facing Bisexual Men”, Journal of Bisexuality, 1: 137-154. DOI: 10.1300/J159v01n02_05.

Gobierno de Canarias (2017), Protocolo para el acompañamiento al alumnado Trans y atención a la diversidad de género en los centros educativos sostenidos con fondos públicos de Canarias [Protocol for the Accompainment of Trans Students and Attention to Gender Diversity in Schools Supported by Public Funds of the Canary Islands]. Available online at http://www.gobiernodecanarias.org/educacion/web/ensenanzas/atencion-a-ladiversidad/protocolo_alumnado_trans.html (last accessed: December 20, 2017).

Gorman, B.K., Denney, J.T., Dowdy, H., and Medeiros, R.A. (2015), "A New Piece of the Puzzle: Sexual Orientation, Gender, and Physical Health Status", Demography, 52: 13571382. DOI: 10.1007/s13524-015-0406-1.

Herek, G.M. (2002), “Heterosexuals' Attitudes toward Bisexual Men and Women in the United States", Journal of Sex Research, 39: 264-274. DOI: 10.1080/00224490209552150.

Israel, T., and Mohr, J.J. (2004), "Attitudes toward Bisexual Women and Men: Current Research, Future Directions", Journal of Bisexuality, 4: 117-134. DOI: 10.1300/J159v04n01_09.

Katz-Wise, S.L., and Hyde, J.S. (2015), “Sexual Fluidity Related Attitudes and Beliefs among Young Adults with a Same-Gender", Archive of Sexual Behaviour, 44: 1459-1470. DOI: 10.1007/s10508-014-0420-1.

Kinnish, K.K., Strassberg, D.S., and Turner, C.W. (2005), "Sex Differences in the Flexibility of Sexual Orientation: A Multidimensional Retrospective Assessment", Archives of Sexual Behavior, 34: 173-183. DOI: 10.1007/s10508-005-1795-9.

Kuhle, B., and Radtke, S. (2013), "Born Both Ways: The Alloparenting Hypothesis for Sexual Fluidity in Women", Evolutionary Psychology, 11: 304-323. DOI: $10.1177 / 147470491301100202$. 
Mahalik, J.R., Locke, B.D., Ludlow, L.H., Diemer, M.A., Scott, R.P.J., Gottfried, M., and Freitas, G. (2003), "Development of the Conformity to Masculine Norms Inventory", Psychology of Men and Masculinity, 4: 3-25. DOI: 10.1037/1524-9220.4.1.3.

Mock, S.E, and Eibach, R.P. (2012), "Stability and Change in Sexual Orientation Identity over a 10-Year Period in Adulthood", Archive of Sexual Behavior, 41: 641-648. DOI: 10.1007/s10508-011-9761-1.

Mohr, J.J., and Rochlen, A.B. (1999), “Measuring Attitudes Regarding Bisexuality in Lesbian, Gay Male and Heterosexual Populations", Journal of Counseling Psychology, 46: 353-369. DOI: 10.1037/0022-0167.46.3.353.

Mulick, P.S., and Wright, L.W. (2002), "Examining the Existence of Biphobia in the Heterosexual and Homosexual Populations", Journal of Bisexuality, 2: 45-64. DOI: 10.1300/J159v02n04_03.

Ott, M.Q., Corliss, H.L., Wypij, D., Rosario, M., and Austin, S.B. (2011), “Stability and Change in Self-Reported Sexual Orientation Identity in Young People: Application of Mobility Metrics", Archives of Sexual Behavior, 40: 519-532. DOI: 10.1007/s10508-010-9691-3.

Pirlott, A.G., and Neuberg, S.L. (2014), "Sexual Prejudice: Avoid in Gun Wanted Sexual Interest?", Social Psychological and Personality Science, 5: 92-101. DOI: $10.1177 / 1948550613486674$.

Rieger, G., and Savin-Williams, R.C. (2012), “The Eyes Have It: Sex and Sexual Orientation Differences in Pupil Dilation Patterns", PLOS ONE, 7: 402-456. DOI: 10.1371/journal.pone.0040256.

Rieger, G., Chivers, M.L., and Badley, J.M. (2005), "Sexual Arousal Patterns of Bisexual Men”, Psychological Science, 16: 579-584. DOI: 10.1111/j.1467-9280.2005.01578.x.

Savin-Williams, R.C., Joyner, K., and Rieger, G. (2012), “Prevalence and Stability of SelfReported Sexual Orientation Identity during Young Adulthood", Archives of Sexual Behavior, 41: 103-110. DOI: 10.1007/s10508-012-9913-y.

Twenge, J.M., Sherman, R.A., and Wells, B.E. (2015), “Changes in American Adults Reported Same-Sex Sexual Experiences and Attitudes, 1972-2012", Archives of Sexual Behavior, 44: 2273-2285. DOI: 10.1007/s10508-016-0769-4.

Twenge, J.M., Sherman, R.A., and Wells, B.E. (2016), “Changes in American Adults Reported Same-Sex Sexual Experiences and Attitudes, 1973-2014", Archives of Sexual Behavior, 45: 1713-1730. DOI: 10.1007/s10508-016-0769-4.

Weiss, J.T. (2004), “GL vs. BT: The Archaeology of Biphobia and Transphobia within the U.S. Gay and Lesbian Community", Journal of Bisexuality, 3: 25-55. DOI: 10.1300/J159v03n03_02.

Yost, M.R., and Thomas, G.D. (2012), “Gender and Binegativity: Men's and Women's Attitudes toward Male and Female Bisexuals", Archives of Sexual Behavior, 41: 691-702. DOI: 10.1007/s10508-011-9767-8.

Zivony, A., and Lobell, L. (2014), "The Invisible Stereotypes of Bisexual Men”, Archives of Sexual Behavior, 43: 1165-1176. DOI: 10.1007/s10508-014-0263-9. 